\title{
An international comparison of adolescent non-suicidal self-injury (NSSI) and suicide attempts: Germany and the USA
}

\author{
P. L. Plener ${ }^{1 *}$, G. Libal ${ }^{2}$, F. Keller ${ }^{1}$, J. M. Fegert ${ }^{1}$ and J. J. Muehlenkamp ${ }^{3}$ \\ ${ }^{1}$ Department of Child and Adolescent Psychiatry and Psychotherapy, University of Ulm, Germany \\ ${ }^{2}$ Department of Child and Adolescent Psychiatry, University of Basel, Switzerland \\ ${ }^{3}$ Department of Psychology, University of North Dakota, USA
}

Background. This study examined the prevalence of non-suicidal self-injury (NSSI), suicide attempts, suicide threats and suicidal ideation in a German school sample and compared the rates with a similar sample of adolescents from the midwestern USA by using cross-nationally validated assessment tools.

Method. Data were provided from 665 adolescents (mean age 14.8 years, S.D. $=0.66$, range $14-17$ years) in a school setting. Students completed the Self-Harm Behavior Questionnaire (SHBQ), the Ottawa Self-Injury Inventory (OSI) and a German version of the Center for Epidemiological Studies-Depression Scale (CES-D).

Results. A quarter of the participants (25.6\%) endorsed at least one act of NSSI in their life, and $9.5 \%$ of those students answered that they had hurt themselves repetitively (more than four times). Forty-three $(6.5 \%)$ of the students reported a history of a suicide attempt. No statistically significant differences were observed between the German and US samples in terms of self-injury or suicidal behaviors.

Conclusions. By using the same validated assessment tools, no differences were found in the prevalence and characteristics of self-injury and suicidal behaviors between adolescents from Germany and the USA. Thus, it seems that NSSI has to be understood as worldwide phenomenon, at least in Western cultures.

Received 30 May 2008; Revised 19 November 2008; Accepted 11 December 2008; First published online 27 January 2009

Key words: Adolescents, deliberate self-harm (DSH), non-suicidal self-injury (NSSI), prevalence, self-injuring behavior (SIB).

\section{Introduction}

Non-suicidal self-injury (NSSI) represents the direct, repetitive, intentional injury of one's own body tissue, without suicidal intent, that is not socially accepted (Lloyd-Richardson et al. 2007). To date, the study of NSSI, especially in relation to its differences from suicidal behavior, has been difficult because of the empirical and conceptual confounding of the variables. This conflation of suicidal and NSSI behaviors is particularly true within European countries, where the construct 'deliberate self-harm' (DSH) is used as an umbrella term for self-destructive behaviors regardless of suicidal intent (Hawton et al. 2007; Madge et al. 2008). Such general terms make cross-cultural comparisons of NSSI difficult, thus hampering research in this area. A considerable amount of literature has

* Address for correspondence : Dr P. L. Plener, Department of Child and Adolescent Psychiatry and Psychotherapy, University of Ulm, Steinhoevelstr. 5, D-89075 Ulm, Germany.

(Email : paul.plener@uniklinik-ulm.de) been published concerning the need to differentiate between self-injuring behavior (SIB) undertaken without suicidal intent and suicidal behaviors undertaken with the intent to die (Nock \& Kessler, 2006; Posner et al. 2007; Silverman et al. 2007). The relationship between these entities is still subject to ongoing research and it is necessary to fully understand the worldwide phenomenon of both sets of behaviors.

Despite the need for a clear nomenclature, it should not be overlooked that NSSI needs to be understood as a potential risk factor for future suicide attempts. A few recent studies have documented the complex relationship between NSSI and suicide risk. Whitlock \& Knox (2007) presented data from an internet survey ( $n=2875$, age range 18-24 years) showing that rates of NSSI were positively correlated with risk for suicidal behavior, meaning that those who injure themselves repetitively were at an increased risk for also having made a suicide attempt. Comparable results were reported by Nock et al. (2006) from an adolescent inpatient sample $(n=89)$. Suicide attempts were more common in adolescents with repetitive self-injuries, 
who injured themselves for a longer period, used different methods of self-injury, and reported feeling no pain during the act of self-injury. Both studies are in accordance with Joiner's (2005) theory that self-injury desensitizes individuals and can increase their risk of later suicide as they habituate to fear and pain. As Whitlock \& Knox (2007) proposed, NSSI should be understood as a signal that the individual engaging in the NSSI is under psychological stress, which could increase risk for suicide attempts.

\section{Prevalence rates}

Recent reports have shown high rates of NSSI in the USA, ranging between $23 \%$ and $38 \%$ in community samples of adolescents and young adults (Ross \& Heath, 2002; Gratz, 2006; Whitlock et al. 2006; LloydRichardson et al. 2007; Muehlenkamp \& Gutierrez, 2007), and a cross-sectional study identified a lifetime course of NSSI with high rates in adolescence and declining rates in young adulthood (Young et al. 2007). Thus, there seems to be consensus that adolescence is an important period in which to study NSSI. Although there are plenty of study-specific data on the prevalence of NSSI in adolescents from the USA, Canada, Australia and the UK (Patton et al. 1997; Hawton et al. 2002; Muehlenkamp \& Gutierrez, 2004; NadaRaja et al. 2004; Skegg et al. 2004; Laye-Gindhu \& Schonert-Reichel, 2005), data on adolescent NSSI are scarce from other Western countries. High rates of NSSI have been found in Turkey, where Zoroglu et al. (2003) reported a lifetime prevalence rate of $21.4 \%$ among 839 students. A prevalence rate of $5.5 \%$ was reported among a sample of Hungarian adolescents (Csorba et al. 2005), and a rate of $24 \%$ was found among young female adults from Italy (Favaro et al. 2007). Rodham et al. (2004) reported a rate of 3.7\% in their British school sample of 6020 adolescents (age range 15-16 years). A Scandinavian study comparing rates of DSH ideation and acts at 12 and 15 years of age reported that, at age $12,2.7 \%$ of the girls and $3.9 \%$ of the boys described DSH ideation and acts, whereas at age $15,12.6 \%$ of the girls and $4.6 \%$ of the boys did so (Sourander et al. 2006). Higher rates were reported more recently by Lundh et al. (2007), who stated that $65.9 \%$ of their Scandinavian adolescent community sample $(n=123$, mean age 15 years) had deliberately harmed themselves and $13.8 \%$ did so repetitively.

The variations in rates of NSSI across countries could be due to cultural influences, but it may be premature to suggest that cultural variables are to blame because there are numerous methodological variations among the existing studies. Different assessment measures and procedures are used across studies, which are frequently based on different conceptions or definitions of self-injury. For example, in the study by Lundh et al. (2007), very high rates of self-injury were reported, and their questionnaire (the Deliberate Self-harm Inventory - simplified version) assessed a range of minor SIBs, such as interference with wound healing and sticking needles under the skin. In comparison, the study of Hungarian adolescents (Csorba et al. 2005) used the Ottawa SelfInjury Inventory (OSI) as the questionnaire that assessed more severe forms of self-harm within another time-frame. In addition, although a broad range of assessment tools do exist, only a few are validated (for a review see Cloutier \& Humphreys, 2008), and even fewer have been cross-validated for use with samples from multiple nationalities.

Data on NSSI from Germany have not been available until recently. The 'Heidelberg school study' (Brunner et al. 2007) assessed DSH within a large adolescent community sample $(n=5759$, mean age 14.9 year), and a 1-year prevalence of $18.9 \%$ was reported. Four per cent of the participants reported repetitive DSH (more than four times) within the year preceding the study. Suicide attempts were reported by $7.9 \%$ and suicidal ideation by $14.4 \%$ of the sample (Brunner et al. 2007). From a clinical sample of admissions $(n=3694)$ to a German emergency department for child and adolescent psychiatry, rates as high as $57 \%$ have been reported using a German assessment instrument, the BaDo (Kirkcaldy et al. 2006). However, none of the studies from these countries assessed their data with internationally validated questionnaires for self-injury. Furthermore, most of the studies included suicidal behaviors in their definitions of DSH, preventing accurate comparisons of NSSI rates to other nations. Results from the latest study comparing the prevalence of DSH crossnationally (Portzky et al. 2008) show that rates of selfharm can differ significantly between neighboring nations (Belgium and The Netherlands). A method to make accurate comparisons regarding NSSI is still needed. No known study has compared rates of NSSI, using cross-nationally validated assessment scales, between differing nations.

The primary aim of this study was to address the assessment limitations of prior international studies of NSSI by using a cross-nationally validated assessment tool to: (1) assess the prevalence of NSSI and suicide attempts in a community sample of German adolescents, and (2) compare German prevalence rates of NSSI and suicide attempts with a comparable sample of adolescents from the midwestern USA (i.e. Muehlenkamp \& Gutierrez, 2007) in order to be able to describe the phenomenon of NSSI in two different nations. 


\section{Method}

\section{Procedures}

We chose to assess rates of NSSI in ninth-grade students to ensure a comparable sample to the US sample previously reported on by Muehlenkamp \& Gutierrez (2007), which we used for comparison in the current study. All schools (with the exception of schools for the intellectually handicapped and special schools for students with disruptive behaviors) within the midsized city Ulm and surrounding rural areas in southern Germany were asked to participate in the current study. Out of 47 eligible schools within this area, 13 agreed to take part. Once a school indicated agreement to participate, all students in the ninthgrade classes were personally informed by P.L.P. about the study, and forms for active parental consent and adolescent assent were distributed. Students were informed that the study focus was on rates of NSSI and suicidal behavior as well as on depressive symptoms, and adolescents were reminded that participation was voluntary and anonymous. Congruent with German legislation on research ethics in studies with minors, participants did not receive any compensation for taking part in the study.

All assessment scales were handed out in the classroom, in sealed envelopes, to those who presented a signed parental consent and adolescent assent form. Only students participating in the study were present in the room. Because of restrictions from the federal school authorities, no personalized information could be obtained from students not participating in the study. The leader of the study (P.L.P.) was present and available in every classroom to answer any questions. After students had completed the assessments they placed their forms back in the envelopes and sealed them. Each adolescent's envelope was then collected by P.L.P. Completing the packet took about 30-45 $\mathrm{min}$. The study and its procedures were approved by the school authorities and the Institutional Review Board of the University of Ulm, Germany.

\section{Ethical issues}

Although it has been argued that filling out a questionnaire concerning suicidal and self-injuring behaviors might lead to suicidal impulses, previous research has not supported these concerns (Gould et al. 2005; Friedman, 2006). Nevertheless, we chose to implement a direct and indirect way of ensuring participant safety. Every participating student was handed out a 'Contact Card' in a separate envelope that included contact details and telephone hours of the study coordinator, which could be used whenever the participants felt they needed to talk to somebody.
As an indirect way of getting in contact with the researchers, students were able to fill out a 'HELP' card, which was provided in a separate envelope, by providing their email address or telephone number if they wanted to be contacted by the study team. Out of 670 participants, seven $(1.04 \%)$ chose to do so. One of the requests turned out to be a hoax, two requested help with minor ailments (seeking help for problems with their friends), and four (0.6\%) who requested help with SIB were provided contact to our out-patient department.

\section{Participants}

A total of 1100 ninth-grade students were available from the participating schools. On the days of assessment 1034 (94\%) students were present, and the rest were missing from school that day. Approximately half of the 1034 students were female $(n=521,50.4 \%)$; $513(49.6 \%)$ were male. Six hundred and seventy $(64.8 \%)$ students were willing and able to participate in the study as they brought their signed parental consent and adolescent assent forms with them. All of these available students returned their assessment packets. Upon review of the assessment packets, one had to be excluded as only age and gender were filled out, and four packets were eliminated because of obvious nonsense or joke answers (all by male participants). This led to the inclusion of 665 participants $(57.1 \%, n=380$ female) for the current analyses. The mean age of participating students was 14.8 years (S.D. $=0.66$, range $14-17$ years). The age of nonparticipating students could not be assessed because of regulations of the school authorities.

\section{Measures}

Self-Harm Behavior Questionnaire (SHBQ; Gutierrez et al. 2001)

The SHBQ is a self-report measure that assesses lifetime prevalence of SHB in four sections: NSSI (e.g. 'Have you ever hurt yourself on purpose?'), suicide attempts (e.g. 'Have you ever attempted suicide?'), suicidal threats (e.g. 'Have you ever threatened to commit suicide?') and suicidal ideations (e.g. 'Have you ever talked or thought about committing suicide?'). Frequency and onset of these behaviors are assessed by follow-up questions that elicit further details about the SHB, such as need for medical attention. The SHBQ has been recommended as a brief screening measure for NSSI (Cloutier \& Humphreys, 2008).

In the original validation study good internal consistency was shown (Cronbach's $\alpha$ ranging between 0.89 and 0.96 for the four sections). This measure has been used in community studies of adolescents in 
the USA (Muehlenkamp \& Gutierrez, 2004, 2007), demonstrating strong psychometric properties in nonclinical and in-patient adolescent samples (Gutierrez \& Osman, 2008), and has recently been validated for use within diverse samples of adolescents (Muehlenkamp et al., unpublished observations). The SHBQ has been translated into German, using a translation and retranslation procedure, and validated for use with German samples by Fliege et al. (2006). They showed a high internal consistency for the German version (Cronbach's $\alpha$ ranging between 0.87 and 0.96 for the four sections). It is important to note that in the German version of the SHBQ, the open-ended question inquiring about methods used for NSSI were omitted to ease completion of the questionnaire. This change proved to be particularly important for the use of the questionnaire in schools, as students often articulated their fear of being recognized (and thus not able to report truly) by their handwriting. Thus, methods of NSSI could only be assessed by the subitem of the OSI in the German sample in a standardized way.

We chose to follow the approach of Muehlenkamp \& Gutierrez (2007), dividing participants based on their responses to the SHBQ into four groups: those with no self-harm (NoSH), those with non-suicidal self-injury only (NSSI), those with suicide attempts only (SA) and those with both NSSI and SA (NSSI+ SA).

Ottawa Self-Injury Inventory (OSI; Nixon et al. 2002)

The OSI is a 21-item questionnaire covering in-depth information on NSSI with regard to 1- and 6-month prevalence rates of NSSI and suicidal behavior and also functions, coping strategies and addictive features (Heath \& Nixon, 2008). Although this measure has been used in a Canadian and Hungarian study (Nixon et al. 2002; Csorba et al. 2005), it has not been formally validated with both German and US samples. To obtain qualitative data on methods of NSSI, we used a translation-retranslation procedure to generate a German version of the OSI. As we chose to focus on reporting and comparing prevalence rates based on measures that have been validated and used in both the USA and Germany, only data on methods of NSSI used were taken from the German-translation OSI.

\section{Statistical analysis}

Mean differences were evaluated with an analysis of variance (ANOVA), with group as the betweensubjects factor (NSSI, NoSH, SA, NSSI+SA) or with $t$ tests in the case of two groups. To detect significant pairwise differences, post-hoc contrasts were performed using the Student-Newman-Keuls test. Categorical variables were analysed by means of $\chi^{2}$ test for frequency tables. All statistical analyses were performed with SAS version 9.1.3 (SAS Institute Inc., Cary, NC, USA).

\section{Results}

German sample: prevalence of NSSI, suicide attempts, suicidal threats and suicidal ideation

NSSI was reported by 170 (25.6\%) of the 665 students (0 missing) completing the study. Participants were asked to indicate how often they injured themselves, and $44(6.6 \%)$ reported doing so only once, $42(6.3 \%)$ reported having hurt themselves twice, and 21 (3.2\%) did so three times. Individuals who reported four or more acts of NSSI comprised $9.5 \%$ of the NSSI group $(n=63)$. Most of the self-injuring participants reported that they had started self-injury within 1 year prior to filling out the questionnaire $(n=103)$, whereas fewer stated that they first injured themselves 2-3 years before $(n=54), 4-5$ years before $(n=7)$, or $\geqslant 6$ years before $(n=5)$. When asked for the 12-month incidence, 161 students (nine missing) with NSSI answered, out of which 132 (82\%) reported having hurt themselves within the past year and 29 (18\%) within the past 24 months. This result means that the 12-month prevalence for NSSI was $19.8 \%$ within the entire sample. Of the 170 participants who reported injuring themselves, $98(57.6 \%)$ said that they had talked with someone about their NSSI and 72 (42.4\%) said that they had not.

From the total sample, 664 students answered the question concerning the history of suicide attempts (one missing). Forty-three (6.5\%) stated that they had attempted suicide, with 26 reporting having made one attempt, 12 reporting two attempts, one making three attempts, and four of the adolescents reported more than three suicide attempts. The question concerning suicidal ideation was answered by 656 participants (nine missing). Two hundred and thirty-nine (36.4\%) of the students stated that they had talked about or thought about taking their lives, and 104 (15.6\%) reported having verbally threatened to attempt suicide (661 responded, four missing). Most of them $(n=71)$ threatened suicide once, 23 threatened two to three times, and nine reported four or more times (one did not report the frequency). Of note, only 44 (42.7\%) reported really wanting to die at the time they made their suicide threats.

\section{Prevalence and gender}

Significant gender differences were found for rates of NSSI [50 males versus 120 females, $\chi^{2}=16.86$, 
Table 1. Clusters of self-harm, gender, place of schooling, suicidal threats and ADS scores

\begin{tabular}{|c|c|c|c|c|}
\hline & \multicolumn{4}{|c|}{ Clusters of self-harm } \\
\hline & $\begin{array}{l}\text { NoSH } \\
(n=484,72.9 \%)\end{array}$ & $\begin{array}{l}\text { NSSI } \\
(n=137,20.6 \%)\end{array}$ & $\begin{array}{l}\text { SA } \\
(n=10,1.5 \%)\end{array}$ & $\begin{array}{l}\text { NSSI + SA } \\
(n=33,5.0 \%)\end{array}$ \\
\hline \multicolumn{5}{|c|}{ Gender, $n(\%)$} \\
\hline Male & $231(47.7)$ & $40(29.2)$ & $3(30.0)$ & $10(30.3)$ \\
\hline Female & $253(52.3)$ & $97(70.8)$ & $7(70.0)$ & $23(69.7)$ \\
\hline \multicolumn{5}{|c|}{ Place of schooling, $n(\%)$} \\
\hline Urban & $252(52.1)$ & $67(48.9)$ & $5(50.0)$ & $14(42.4)$ \\
\hline Rural & $232(47.9)$ & $70(51.1)$ & $5(50.0)$ & $19(57.6)$ \\
\hline \multicolumn{5}{|c|}{ Suicidal threats, $n(\%)$} \\
\hline Yes & $37(7.7)$ & $46(33.8)$ & $3(30.0)$ & $18(56.3)$ \\
\hline No & $446(92.3)$ & $90(66.2)$ & $7(70.0)$ & $14(43.7)$ \\
\hline \multicolumn{5}{|c|}{ ADS score, mean (s.D.) } \\
\hline Female & $16.13(8.66)$ & $24.28(10.02)$ & $24.86(7.56)$ & $30.48(8.78)$ \\
\hline Male & $10.95(6.72)$ & $18.23(10.91)$ & $22(19.95)$ & $17.60(6.70)$ \\
\hline Total & $13.66(8.21)$ & $22.51(10.61)$ & $24(11.34)$ & $26.68(10.09)$ \\
\hline
\end{tabular}

ADS, Depression scale (Allgemeine Depressions Skala); NoSH, no self-harm; NSSI, non-suicidal self-injury; SA, suicide attempt; S.D., standard deviation.

$p<0.0001$, odds ratio (OR) $2.17,95 \%$ confidence interval (CI) 1.49-3.15]. Females were also more likely than males to report talking to others about their NSSI $\left(\chi^{2}=13.59, p<0.001\right.$, OR 3.56, 95\% CI 1.78-7.1). Although more females reported suicide attempts (13 males versus 30 females), the difference was not statistically significant $\left(\chi^{2}=2.95, p=0.09\right.$, OR $1.79,95 \%$ CI 0.91-3.49). However, statistically significant differences were found for having threatened to attempt suicide (28 males versus 76 females, $\chi^{2}=12.50, p<$ 0.001 , OR $2.28,95 \%$ CI 1.34-3.62) and for reports of suicidal ideation (72 males versus 167 females, $\chi^{2}=$ 24.20, $p<0.0001$, OR 2.31, 95\% CI 1.65-3.23).

\section{Prevalence in urban versus rural areas}

No statistically significant differences were found on any of the four SHBQ categories between students from town or country schools (NSSI: 89 town versus 81 country, $\chi^{2}=1.01, p=0.31$, OR $1.20,95 \%$ CI $0.84-1.7$; suicidal attempts: 24 town versus 19 country, $\chi^{2}=0.83$, $p=0.36$, OR $1.33,95 \%$ CI $0.72-2.49$; suicidal threats : 46 town versus 58 country, $\chi^{2}=1.2, p=0.27$, OR $0.79,95 \%$ CI 0.52-1.20; suicidal ideation: 113 town versus 126 country, $\chi^{2}=0.67, p=0.41$, OR $0.88,95 \%$ CI $0.64-1.20$ ).

\section{Clusters of self-harm}

Participants were divided into four self-harm groups (NoSH, NSSI, SA, NSSI+SA; see Method section), with frequencies provided in Table 1 . There was a significant association with gender, with girls showing a 50:50 ratio in the $\mathrm{NoSH}$ group and a 70:30 ratio in the NSSI, SA and NSSI +SA groups $\left(\chi^{2}=17.93, \mathrm{df}=3\right.$, $p<0.001)$; this reflects the gender differences noted earlier. Suicidal threats were significantly related to the four clusters of self-harm $\left(\chi^{2}=98.47, \mathrm{df}=3, p<\right.$ 0.0001). There was no significant relationship between clusters and place of schooling (urban versus rural, $\left.\chi^{2}=1.43, \mathrm{df}=3, p=0.70\right)$.

\section{Comparison between Germany and US samples}

As one of the aims of this paper was to compare rates of NSSI and suicidal behavior in the USA and Germany, a closer comparison of the two populations was necessary (details are provided in Table 2). Both groups were recruited from schools situated in and around midsized cities, using similar recruitment strategies, research methodology, and active parental consent (see Muehlenkamp \& Gutierrez, 2007 for details on US methods). Although the German sample was slightly larger in size (665 v. 540 in the US sample), the gender balance was comparable in both groups $\left(\chi^{2}=3.19, \mathrm{df}=1, p=0.07\right.$, OR 1.24, 95\% CI 0.98-1.56). Differences exist in age, with the US sample being slightly older $(t=11.02, \mathrm{df}=726, p<0.0001)$. When comparing the frequencies in the four clusters of selfharm, no statistically significant differences were 
Table 2. US and German sample characteristics

\begin{tabular}{lcc}
\hline & $\begin{array}{l}\text { US } \\
\text { sample }\end{array}$ & $\begin{array}{l}\text { German } \\
\text { sample }\end{array}$ \\
\hline$n$ & 540 & 665 \\
Age in years, mean (s.D.) & $15.53(1.42)$ & $14.8(0.66)$ \\
Gender (female:male), $n(\%)$ & $336: 204$ & $380: 285$ \\
& $(62.3: 37.7)$ & $(57.1: 42.9)$ \\
NoSH (\%) & 75.2 & 72.4 \\
NSSI (\%) & 16.1 & 20.5 \\
SA (\%) & 1.9 & 1.66 \\
NSSI +SA (\%) & 7.0 & 5.5 \\
\hline
\end{tabular}

NoSH, No self-harm; NSSI, non-suicidal self-injury; SA, suicide attempt; S.D., standard deviation.

found between the US and the German school populations $\left(\chi^{2}=5.85, \mathrm{df}=3, p>0.10\right)$.

\section{Methods of self-injury}

Methods used for NSSI in the German sample were assessed by using a list of 18 possible methods taken from the OSI, including both impulsive and compulsive forms of NSSI (according to Favazza, 1998 and Favaro et al. 2007). The most prevalent methods were severe scratching $(n=49,27.22 \%)$, cutting $(n=45$, $25 \%)$ and hitting oneself $(n=21,11.67 \%)$. In the US sample, the methods of NSSI were assessed by an open-ended question ('Have you ever hurt yourself on purpose? If yes, what did you do?'). The main methods of NSSI reported in the US sample were cutting $(n=65,48.15 \%)$, severe scratching $(n=36,26.67 \%)$ and hitting oneself $(n=15,11.11 \%)$ (Muehlenkamp \& Gutierrez, 2007; further details are provided in Table 3). When comparing the three most prevalent methods, we found that cutting was more frequent in the US sample $\left(\chi^{2}=18.19, p<0.0001\right.$, OR $2.79,95 \% \mathrm{CI}$ 1.73-4.49) whereas no statistical significant differences were found for severe scratching $\left(\chi^{2}=0.01, p=0.91\right.$, OR $0.97,95 \%$ CI $0.59-1.61)$ or hitting oneself $\left(\chi^{2}=0.02\right.$, $p=0.89$, OR $0.95,95 \%$ CI 0.47-1.91).

\section{Discussion}

This study describes prevalence rates of NSSI and suicidal behaviors in a German school sample and compares these rates to data from a recent US sample (Muehlenkamp \& Gutierrez, 2007) using comparable groups and study designs. Although studies on the prevalence of NSSI, or DSH, have been undertaken before, many have been restricted to English-speaking countries and failed to use cross-nationally validated assessment tools of NSSI. As a result, our findings permit more accurate comparisons between samples from different nations because a standard definition and assessment tool was used. Thus, confidence can be maintained when interpreting our findings and drawing initial conclusions about the prevalence of NSSI among adolescent populations in Western countries.

Data from the current study suggest that rates of NSSI and suicide attempts are comparable between German and US school students. Specifically, it was noted that $25.6 \%$ of the German adolescents endorsed at least one act of NSSI. This rate is consistent with rates reported across many different studies conducted from English-speaking countries (Muehlenkamp \& Gutierrez, 2004; Laye-Gindhu \& Schonert-Reichel, 2005; Lloyd-Richardson et al. 2007) and is similar to the US comparison sample rate of $23.2 \%$ (Muehlenkamp \& Gutierrez, 2007). Similarly, the primary methods of NSSI (cutting, scratching, hitting oneself) were comparable between the US and the German sample, although cutting was more prevalent in the US sample. However, this difference in NSSI methods must be interpreted with caution because the assessment tool for this variable was not similar between samples, and German adolescents were asked for behaviors within the past month whereas lifetime prevalence of NSSI methods was assessed in the US sample. In general, the current data support the conclusion that the basic features of NSSI are similar between US and German students.

To date, only two known studies have compared prevalence rates of DSH in European countries, finding somewhat different results between countries (Madge et al. 2008; Portzky et al. 2008). However, the definition used for DSH did not permit clear differentiation between acts undertaken with or without suicidal intent. As large differences in suicide mortality rates have been observed between Belgium and The Netherlands, these findings on self-harm are potentially confounded by suicidal behaviors (Portzky et al. 2008). Thus, additional studies that use a clear distinction between self-injury and suicidal behavior, such as our own, are needed to understand the phenomenon of NSSI across cultures. Our results, in which NSSI was clearly differentiated from suicidal behaviors, indicate that significant differences in rates of NSSI and suicidal behavior between Germany and US adolescents do not exist. Furthermore, we found that the lifetime prevalence rates were similar in both the German and US samples across the different clusters of self-harm. These findings suggest that NSSI and suicidal behaviors in adolescents may represent a similar level of problematic behavior regardless of the country of origin.

In addition to finding similarities in basic rates and method of NSSI, we also found important 
Table 3. Methods of self-harm in the German and US samples

\begin{tabular}{|c|c|c|c|c|c|c|}
\hline \multirow[b]{2}{*}{ Method } & \multicolumn{3}{|c|}{ German sample } & \multicolumn{3}{|c|}{ US sample } \\
\hline & $\begin{array}{l}\text { NSSI } \\
(n=137)\end{array}$ & $\begin{array}{l}\text { SA } \\
(n=10)\end{array}$ & $\begin{array}{l}\text { NSSI +SA } \\
(n=33)\end{array}$ & $\begin{array}{l}\text { NSSI } \\
(n=87)\end{array}$ & $\begin{array}{l}\text { SA } \\
(n=10)\end{array}$ & $\begin{array}{l}\text { NSSI + SA } \\
(n=38)\end{array}$ \\
\hline Cut & 32 & 1 & 12 & 48 & 3 & 14 \\
\hline Scratch & 38 & 0 & 11 & 36 & 0 & 0 \\
\hline Burn & 4 & 0 & 2 & 5 & 0 & 0 \\
\hline Self-hit & 15 & 0 & 6 & 15 & 0 & 0 \\
\hline Punch/kick & - & - & - & 9 & 0 & 0 \\
\hline Banging & 0 & 0 & 0 & 3 & 0 & 0 \\
\hline Hair pulling & 4 & 0 & 0 & - & - & - \\
\hline Severe nail biting/nail injuries & 6 & 0 & 4 & - & - & - \\
\hline Breaking bones & 2 & 0 & 1 & - & - & - \\
\hline Interference with wound healing & 10 & 0 & 0 & - & - & - \\
\hline Other method & 34 & 0 & 6 & 16 & 8 & 4 \\
\hline Use of 1 method & 14 & 0 & 4 & 61 & 9 & 16 \\
\hline Use of $\geqslant 2$ methods & 98 & 10 & 16 & 17 & 1 & 20 \\
\hline
\end{tabular}

NoSH, No self-harm; NSSI, non-suicidal self-injury; SA, suicide attempt.

Methods in the US sample were assessed by using the Self-Harm Behavior Questionnaire (SHBQ); methods in the German sample were assessed by using the Ottawa Self-Injury Inventory (OSI) (methods used within the past month).

co-occurrences between suicidal behaviors and NSSI. Globally, a majority of students who reported a suicide attempt also reported having engaged in NSSI. Additionally, suicidal ideation was more prevalent among self-injurers with a suicide attempt than those with only NSSI, and students without any SHBs. These results are consistent with previous studies exploring distinctions between NSSI and suicidal behaviors (Muehlenkamp \& Gutierrez, 2004; Nock et al. 2006; Whitlock \& Knox, 2007), and are in accordance with Joiner's theory (2005) suggesting that NSSI may contribute to a type of habituation that increases risk for suicidal behaviour. The consistencies across studies, and nationalities, speak to a potential uniformity of these self-destructive behaviors that implies that generalizations could be made from studies using samples of varied nationality.

In our study SIBs were particularly prevalent among female adolescents. Girls reported NSSI, suicidal threats and suicidal ideation twice as frequently as boys. However, no statistical gender difference could be found concerning suicidal attempts. Significant gender differences could be found in all clusters of self-harm (NSSI, SA, NSSI + SA), which is partly in accordance with the findings of Muehlenkamp \& Gutierrez (2007), who reported significant gender differences in the NSSI+SA group but not in the NSSI or the SA group. Other recent studies have shown higher rates of NSSI or DSH in female adolescents (Sourander et al. 2006; Brunner et al. 2007; Patton et al. 2007; Madge et al. 2008; Portzky et al.
2008). However, studies in Swedish and US adolescents of about the same age as our sample did not reveal significant gender differences in rates of DSH or NSSI (Lloyd-Richardson et al. 2007; Lundh et al. 2007), which was also the case in a study of young Scottish adults (Young et al. 2007). In the light of these different findings it should be noted that the question of gender differences in NSSI and DSH is still unclear, and needs to be studied further (Jacobson \& Gould, 2007).

The results from this study also expand our current understanding of the phenomenon of self-injury within Germany. To date there has been only one school study providing data on self-harming behaviors (DSH) in Germany (Brunner et al. 2007). Comparable rates of DSH $(18.9 \%$ v. $19.8 \%$ 1-year prevalence in our sample) and suicide attempts (7.9\% v. $6.5 \%$ ) were found between Brunner et al.'s study (2007) and the current study. The rates of suicidal ideation differed $(14.4 \%$ v. $36.4 \%$ in our sample), which may have been due to the different assessment tools used and timelines for reporting (1-year versus lifetime). Even though different assessment tools were used, rates of NSSI and suicide attempts are similar, suggesting that the rates found in the current study may be representative of the larger adolescent population within Germany. As data of the cited study were assessed in the context of a broader study on lifestyle in adolescence, our study is the first in Germany to specifically assess NSSI in adolescents using validated tools. 


\section{Limitations}

This study has some limitations that should be noted. Participation was contingent upon receiving positive informed consent of the parents and assent of the students. Although our response rate $(64.8 \%$ of the students and their parents) is adequate and comparable to other studies, because of school authority regulations we have no data on the reasons for not participating in the study. Based on remarks from teachers and non-participating students, our impression was that failure to return the consent and assent forms at the chosen date was the main obstacle for the students. However, it is also possible that some of the students who did not have authorization to participate may have been those at greater risk for NSSI (Tigges, 2003), which could limit the generalizability of our findings. It was pointed out by Jacobson \& Gould (2007) that true rates of NSSI may be higher than that assessed by school studies as students who were truant or had withdrawn from school are not included. However, it should be noted that our study was advertised as a study on self-injury, which may have created a selection bias.

Another limitation is that our study fails to provide data on ethnicity. This is due to the reality that Germany has a fairly homogeneous population, with the majority of inhabitants being Caucasian. As we were not allowed to collect data from nonparticipating students, question for ethnicity would have made little sense as we would not have been able to compare participants to the whole group. Another weakness of our study is that the US version of the SHBQ assesses methods of NSSI by using an openended question, but this question was omitted from the German version. We therefore had to compare the phenomenology of NSSI using the OSI, which diminishes generalizability of this comparison, although it is important to note that data from the two different instruments do provide information that is similar. Finally, one other limitation is that the data involved self-reported retrospective recall of NSSI and suicidal behaviors. Although self-report questionnaires are the standard methodological approach for studying such behaviors, they are subject to response biases. Requesting adolescents to report on behaviors that have happened in the past, in some cases up to 2 years prior to the survey, may have led to some memory errors. Thus, all data should be interpreted with caution.

In summary, this study adds further evidence that NSSI has to be understood as a worldwide phenomenon, at least in Western cultures. Recent studies of adolescents show high prevalence rates for NSSI (Brunner et al. 2007; Lloyd-Richardson et al. 2007;
Lundh et al. 2007) across continents, suggesting the need to engage in cross-cultural explorations of this behavior. It can only be hypothesized where these consistently high prevalence rates might emerge from. One hypothesis is that the worldwide distribution of NSSI may be due, in part, to findings that self-injury represents a prevalent content in the World Wide Web (Whitlock et al. 2006), and people with NSSI tend to use the Internet more and make more use of chat rooms (Mitchell \& Ybarra, 2007). NSSI can also be found in certain youth subcultures (Young et al. 2006) and it is also possible that certain elements consistent within Western cultures play a role in the development of NSSI behaviors. To better understand this phenomenon and explain sociocultural and psychological factors associated with NSSI, cross-cultural studies are highly relevant and need to be conducted. To do this, a unified nomenclature is needed along with the use of standardized, cross-culturally validated assessment tools. Studies using longitudinal designs are also necessary to evaluate the life course and trajectories of NSSI among adolescents living within different countries.

\section{Acknowledgements}

This work was financed by the University of Ulm.

\section{Declaration of Interest}

None.

\section{References}

Brunner R, Parzer P, Haffner J, Steen R, Roos J, Klett M, Resch F (2007). Prevalence and psychological correlates of occasional and repetitive deliberate self-harm in adolescents. Archives of Pediatrics and Adolescent Health 161, 641-649.

Cloutier P, Humphreys L (2008). Measurement of nonsuicidal self-injury in adolescents. In Self-Injury in Youth (ed. M. K. Nixon and N. L. Heath), pp. 115-142. Routledge: New York.

Csorba J, Szelesne EF, Steiner P, Farkas L, Nemeth A (2005). Symptom specificity of adolescents with self-injurious behavior. Psychiatria Hungarica 20, 456-462.

Favaro A, Ferrara S, Santonastaso P (2007). Self-injurious behavior in a community sample of young women: relationship with childhood abuse and other types of self-damaging behaviors. Journal of Clinical Psychiatry 68, 122-131.

Favazza AR (1998). The coming of age of self-mutilation. Journal of Nervous and Mental Disease 186, 259-268.

Fliege H, Kocalevent RD, Walter OB, Gratz KL, Gutierrez PM, Klapp BF (2006). Three assessment tools for deliberate self-harm and suicide behaviour: evaluation 
and psychopathological correlates. Journal of Psychosomatic Research 61, 113-121.

Friedman RA (2006). Uncovering an epidemic - screening for mental illness in teens. New England Journal of Medicine 355, 2717-2719.

Gould MS, Marrocco FA, Kleinmann M, Thomas JG, Mostkoff K, Cote J, Davies M (2005). Evaluating iatrogenic risk of youth suicide screening programs. Journal of the American Medical Association 293, 1635-1643.

Gratz KL (2006). Risk factors for deliberate self-harm among female college students: the role and interaction of childhood maltreatment, emotional inexpressivity, and affect intensity/reactivity. American Journal of Orthopsychiatry 76, 238-250.

Gutierrez PM, Osman A (2008). Adolescent Suicide: An Integrated Approach to the Assessment of Risk and Protective Factors. Northern Illinois University Press: DeKalb, IL.

Gutierrez PM, Osman A, Barrios FX, Kopper BA (2001) Development and initial validation of the self-harm behavior questionnaire. Journal of Personality Assessment 77, 475-490.

Hawton K, Bergen H, Casey D, Simkin S, Palmer B, Coooper J, Kapur N, Horrocks J, House A, Lilley R, Noble R, Owens D (2007). Self-harm in England: a tale of three cities. Social Psychiatry and Psychiatric Epidemiology 42, 513-521.

Hawton K, Rodham K, Evans E, Weatherall R (2002). Deliberate self-harm in adolescents: self-report survey in schools in England. British Medical Journal 325, 1207-1211.

Heath NL, Nixon MK (2008). Assessment of nonsuicidal self-injury in youth. In Self-Injury in Youth (ed. M. K. Nixon and N. L. Heath), pp. 143-170. Routledge: New York.

Jacobson CM, Gould M (2007). The epidemiology and phenomenology of non-suicidal self-injurious behavior among adolescents: a critical review of the literature. Archives of Suicide Research 11, 129-147.

Joiner T (2005). Why People Die by Suicide. Harvard University Press: Cambridge, MA.

Kirkcaldy BD, Brown J, Siefen RG (2006). Disruptive behaviour disorders, self harm and suicidal ideation among German adolescents in psychiatric care. International Journal of Adolescent Medicine and Health 18, 597-614.

Laye-Gindhu A, Schonert-Reichl KA (2005). Nonsuicidal self-harm among community adolescents: understanding the 'whats' and 'whys' of self-harm. Journal of Youth and Adolescence 34, 447-457.

Lloyd-Richardson EE, Perrine N, Dierker L, Kelley ML (2007). Characteristics and functions of non-suicidal selfinjury in a community sample of adolescents. Psychological Medicine 37, 1183-1192.

Lundh LG, Karim J, Quilisch E (2007). Deliberate self-harm in 15-year-old adolescents : a pilot study with a modified version of the Deliberate Self-Harm Inventory.

Scandinavian Journal of Psychology 48, 33-41.

Madge N, Hewitt A, Hawton K, de Wilde EJ, Corcoran P, Fekete S, van Heeringen K, De Leo D, Ystgaard M (2008). Deliberate self-harm within an international community sample of young people: comparative findings from the Child \& Adolescent Self-Harm in Europe (CASE) study. Journal of Child Psychology and Psychiatry 49, 667-677.

Mitchell KJ, Ybarra ML (2007). Online behaviour of youth who engage in self-harm provides clues for preventive intervention. Preventive Medicine 45, 392-396.

Muehlenkamp JJ (2005). Self-injurious behavior as a separate clinical syndrome. American Journal of Orthopsychiatry 75, 324-333.

Muehlenkamp JJ, Gutierrez PM (2004). An investigation of differences between self-injurious behavior and suicide attempts in a sample of adolescents. Suicide and LifeThreatening Behavior 34, 12-23.

Muehlenkamp JJ, Gutierrez PM (2007). Risk for suicide attempts among adolescents who engage in non-suicidal self-injury. Archives of Suicide Research 11, 69-82.

Nada-Raja S, Skegg K, Langley J, Morrison D, Sowerby P (2004). Self-harmful behaviors in a population-based sample of young adults. Suicide and Life-Threatening Behavior 34, 177-186.

Nixon MK, Cloutier PF, Aggarwal S (2002). Affect regulation and addictive aspects of repetitive self-injury in hospitalized adolescents. Journal of the American Academy of Child and Adolescent Psychiatry 41, 1333-1341.

Nock MK, Joiner Jr. TE, Gordon KH, Lloyd-Richardson E, Prinstein MJ (2006). Non-suicidal self-injury among adolescents: diagnostic correlates and relation to suicide attempts. Psychiatry Research 30, 65-72.

Nock MK, Kessler RC (2006). Prevalence and risk factors for suicide attempts versus suicide gestures: analysis of the National Comorbidity Survey. Journal of Abnormal Psychology 115, 616-623.

Patton GC, Harris R, Carlin JB, Hibbert ME, Coffey C, Schwartz M, Bowes G (1997). Adolescent suicidal behaviours: a population-based study of risk. Psychological Medicine 27, 715-724.

Patton GC, Hemphill SA, Beyers JM, Bond L, Toumbourou JW, McMorris BJ, Catalano RF (2007). Pubertal stage and deliberate self-harm in adolescents. Journal of the American Academy of Child and Adolescent Psychiatry 46, 508-514.

Portzky G, De Wilde EJ, van Heeringen K (2008). Deliberate self harm in young people: differences in prevalence and risk factors between The Netherlands and Belgium. European Child and Adolescent Psychiatry 17, 179-186.

Posner K, Oquendo MA, Gould M, Stanley B, Davies M (2007). Columbia Classification Algorithm of Suicide Assessment (C-CASA) : classification of suicidal events in the FDA's pediatric suicidal risk analysis of antidepressants. American Journal of Psychiatry 164, 1035-1043.

Rodham K, Hawton K, Evans E (2004). Reasons for deliberate self-harm: comparison of self-poisoners and self-cutters in a community sample of adolescents. Journal of the American Academy of Child and Adolescent Psychiatry 43, 80-87.

Ross S, Heath N (2002). A study of the frequency of selfmutilation in a community sample of adolescents. Journal of Youth and Adolescence 31, 67-77.

Silverman MM, Berman AL, Sanddal ND, O'Carroll PW, Joiner TE (2007). Rebuilding the tower of Babel: a revised 
nomenclature for the study of suicide and suicidal behaviors. Part 2: Suicide-related ideations, communications and behaviors. Suicide and Life-Threatening Behavior 37, 264-277.

Skegg K, Nada-Raja S, Moffitt TE (2004). Minor self-harm and psychiatric disorder: a population-based study. Suicide and Life-Threatening Behavior 34, 187-196.

Sourander A, Aromaa M, Pihlakoski L, Haavisto A, Rautava P, Helenius H, Sillanpaa M (2006). Early predictors of deliberate self-harm among adolescents. A prospective follow-up study from age 3 to age 15 . Journal of Affective Disorders 93, 87-96.

Tigges BB (2003). Parental consent and adolescent risk behavior research. Journal of Nursing Scholarship 35 283-289.

Whitlock J, Eckenrode J, Silverman D (2006). Self-injurious behaviors in a college population. Pediatrics 117, 1939-1948.

Whitlock J, Knox KL (2007). The relationship between self-injurious behaviour and suicide in a young adult population. Archives of Pediatrics and Adolescent Medicine 161, 634-640.

Whitlock J, Powers JL, Eckenrode J (2006). The virtual cutting edge: the internet and adolescent self-injury. Developmental Psychology 42, 407-417.

Young R, Sweeting H, West P (2006). Prevalence of deliberate self-harm and attempted suicide within contemporary Goth youth subculture: longitudinal cohort study. British Medical Journal 332, 1058-1061.

Young R, van Beinum M, Sweeting H, West P (2007). Young people who self-harm. British Journal of Psychiatry 191, 44-49.

Zoroglu SS, Tuzun U, Sar V, Tutkun H, Savacs HA, Ozturk M, Alyanak B, Kora ME (2003). Suicide attempt and self-mutilation among Turkish high school students in relation with abuse, neglect and dissociation. Psychiatry and Clinical Neurosciences 57, 119-126. 